\title{
The Phenomenon of the Aesthetic in Musical Co- Creation
}

\author{
Vitaly Kalitzky \\ Russian State Specialized Academy of Arts \\ Moscow, Russia
}

\begin{abstract}
This article discusses the most significant aesthetic problems of performing in ensembles. Music ensemble appears not only as the quintessence and Smysloviye aesthetic, cultural philosophy, social shifts of the era, but also as a concept conducive to the most effective ways to address the critical issues and problems of our time. The work actualizes the specifics of individual and collaborative ensemble in the culture as a kind of aesthetic component necessary for solving problems interpretation of a musical work as an artistic whole. The author raises the question of the need to develop integrated methodologies to study the investigated phenomenon, based on advances in the field of aesthetics, cultural philosophy, art history, at the intersection of a whole range of disciplines. The specificity of the ensemble of culture is revealed not only as a musicological concept, but also as a unique aesthetic category. The aesthetic sense of a musical ensemble is parsed as a bi-directional personal-social and communication concept, which is a universal communication and, nevertheless, an individual constant that allows this two-pronged direction most effectively to achieve a cohesive artistic decisions in the process of deciphering and implementation of songwriting. This provision creates for the performers' interpretations of the most fertile soil, and the recipient as a result is transmitted to the most objective and full information and emotional picture of the work.
\end{abstract}

Keywords-music; co-creation; aesthetics; ensemble performance; recipient; communication; individual; joint; harmony; integrity

\section{INTRODUCTION}

The question of aesthetic attainment of professional ensemble music-making seems to be relevant because of its studies and, along with this, the urgent need to understand it for aesthetic thought, and for musicians. Peculiar, unique situation ensemble performing at the joint existence of various forms of music-making was noticed by Aristotle [1] [2], who pointed to its categorical characterization, which belongs to Supreme harmony, that allows us to judge what this kind of musical practice from ancient times were erected to the rank of musical aesthetics, representing the highest form of manifestation of the human spirit.

A noticeable increase of interest in ensemble work, as well as tangible improvements in social status of the ensemble at the present stage of existence and development of world history and culture marks the evolution of the deep cultural and socio-dynamic processes occurring at various ontological levels of human development.

Despite the huge interest in musician-practitioners and the "real" picture of a dynamic ensemble performance, ensemble phenomenon of culture is one of the smaller aesthetic categories. To the study of ensemble music-making turn, as a rule, either on the concrete empirical level, the pedagogical and musical practice, either in the context of historical and theoretical awareness of a product.

\section{ThE Genesis OF THE AESTHETIC IN MUSIC ENSEMBLE}

The most acute problem of modern aesthetics is the study of the theoretical and methodological features of ensemble creativity as a separate paradigm of science, involving the study and analysis of the ontological foundation of the musical ensemble as a multifunctional phenomenon with inherent aesthetic, cultural philosophy, social and communicative functions.

This approach draws us to the development of a new methodological concept, based not only on fundamental aesthetic position, but also on the performing and interpretative content of a musical work that combines aesthetic, cultural philosophy, historical and practical concept of ensemble skills [3].

First, the aesthetic property of the ensemble performance that should be noted is the commonality. In the fundamental work of P. Florensky "the Pillar and ground of the truth. The experience of Orthodox theodicy" [4] in which the author explains the nature of aesthetic culture not as a unified spatial-temporal process, and not as an evolutionary paradigm, but as an objective unity, indicates that the highest achievement of aesthetic harmony is possible only through joint understanding and identification of themselves as part of cosmic existence. As a collaborative effort, ensemble music performance puts this function directly into practice. The aesthetic harmony of musical co-creation is one of the strategic poles of the antinomy of musical art. Musical aesthetic language of ensemble works is a unique semiotic structure in which a real fixation and the practical use of the lexical elements of the music of genesis defines a joint performance. Then, as a result of aesthetic cognition of artistic interpretation of a musical work, they acquire their meaning. No doubt, strictly fixed rules are not a 
characteristic feature of the ensemble. It should be noted that many symbolic melodic turns (for example, the medieval sequence Dies irae, in the Catholic Liturgy are used as a proprioceptive mass, narrating the Day of wrath (judgment day) used in the works of composers of different eras ("Fantastic Symphony" by H. Berlioz and "Danse macabre" by C. Saint-Saens as an example of the collective creativity of the ensemble; Paraphrase on the Dies irae "Totentanz" of Franz Liszt and "Rhapsody on a theme of Paganini" by Sergei Rachmaninov as an example of co-creation ensemble soloist and orchestra; Quintet for piano and strings $\mathrm{N}$. Medtner - the sample chamber-instrumental ensemble, vocal composition "Our age" - the ensemble of voice and piano, etc.) are sealed semiotic structures in an existing musical practice, and are the signs and ligaments, allowing musicians to decrypt the text and accurately identifying common points of content and the appropriate interpretation.

\section{RECIPIENT NAME FUNCTION MUSICAL ENSEMBLE PERFORMANCE}

Following the aesthetic quality inherent in the ensemble culture is characterized by organic unity of individual and obshego. The individual exists in each performer participating in the ensemble, but each of their aesthetic perceptions of the qualitatively are diverse and has a specific recipient info structure and orientation. The combination of various ontological representations stored in auditory and developing the experience of any member of collective music-making form a unique society. The structure of the inner ear musicians in the polyphonic ensemble: facing the surrounding "sounding the world", hearing unceasingly transforms, transforms, combines the events, thoughts and impressions. In this way, the current auditory space by the individual is transformed and directs their attention to the aesthetic essence of the interpreted works. Exactly this method is the formation of a productive musical aestheticdialogical thinking. One of the fundamental features of musical-aesthetic messages in the ensemble is the gnosis of the creative act - from the composer's mind to the recipient of knowledge. The Chinese philosopher Mencius, wrote about ensemble performance: "What is more pleasing one to enjoy music or together with others? Better together with others. What is nicer - with a few enjoy it together or with many? Better together with many" [5]. The aesthetic sense of the ensemble has a bidirectional personal and social and communication function, the specifics of which how exactly are informative and, along with this deeply emotional factor, is that only in the interaction of individual and personal interest, intensive joint search single artistic decision the objective content of the songwriting for artists creates the most fertile ground for interpretation, and the recipient as a result is transmitted to the most objective and full information and emotional picture of the work. Under the aesthetic perspective of the ensemble culture is aware of such categorical characteristics, which often remain invisible in exclusively musicological approach. Music, art hearing, when this is revealed most fully mobile, unlike stable arts visual range of painting, sculpture, architecture. In the joint culture of musical performance there are two types of variant coexistence of historical and directly ensemble [6]. Historical occurs together with the change of epochs, cultural change, change of ethical and aesthetic ideals, etc. Ensemble the group of performers, transformed and synthesized within their individual style. The performers in most cases understand that the modern interpretation of the works can take away from the understanding of the content of composition and concepts of the composer himself. Born in this dilemma - the problem of choice between tradition and modern (often biased) musicians practice the vast majority hold positions of contemporary interpretation. L. Auer pointed out that there can exist one fixed way of interpretation by the performer of a musical work, because there is no steadfast, the reference criterion of awareness is beautiful. Method and manner of performance, adopted at one historical time may be completely unacceptable in another [7]. In this case most clearly come to the four basic aesthetic categories of beauty and ugliness. What is the choice? This question always remains within "the conscience" of many musicians, but in any case the management of the higher ideals of Harmony and Light must be guiding their work. Reliance and desire for beauty not only gives a moral right to broadcast the sacred information stored in the musical composition, but by playing music and allows you to achieve inner perfection, thereby transforming its appearance aesthetically.

Ensemble culture, is of huge significance in the ontological knowledge, including basic personality traits, dominance of the relevant thoughts of his time and varied aspirations of his aesthetic reflection. The social orientation of the ensemble of culture is aimed directly at understanding personal relationships, understanding of vzaimovliyaniya, and, as a final goal, - to an extensive dialogue, the elimination of fragmentation and psychological barriers, the achievement of spiritual harmony. P. Ricoeur noted that in an ensemble co-creation touching a fundamentally different aesthetic positions. A distinctive specific feature of the creative work of P. Ricoeur, is the desire to "think together position, often acting as antinomical" [8].Thus, the P. Ricoeur shows the relevance of ensemble performance and its aesthetic semantics.

Identifying the aesthetic essence of contemporary ensemble partnership is a critical issue. Joint performance carries a powerful intellectual, spiritual and emotional a consolidating action, which is realized in actual practice musical communication. The aesthetic purpose of the ensemble is extremely important in our time - a time of acute political, social, economic, ethnic upheavals and shifts. It is in joint music-making of the XXI century clearly there is an aesthetic tendency towards confrontation antiduhovnosti of our era, the resistance increase in the indifference, callousness and cruelty. P. Hindemith in his "World composer" writes: "the Russian Chairman of the Presidium of the Supreme Soviet and the American President, along with his other colleagues could at least once a week to play and sing in an Amateur ensemble, thereby showing to the world the example of an initiative directed to lofty goals, and then the fate of humanity would be resolved in the best way" [9]. 


\section{REFERENCES}

[1] Losev A. F. History of ancient aesthetics. Aristotle and later classics. Volume IV. Moscow, 1975. S. 637.

[2] J. van der Meulen. Aristoteles. Die Mitte in seinem Denken. Meisenheim, 1951. R. 124-125.

[3] Kalitzky V. Dialogue in the musical communication as a cultural phenomenon (the philosophical and cultural analysis). The dissertation on competition of a scientific degree of candidate of philosophical Sciences. M., 2014. P. 129-139.

[4] Florensky P. A. The Pillar and ground of the truth. The experience of Orthodox theodicy. M: The Way, 1914. 814 p.

[5] Musical aesthetics of the East // edited by V. P. Shestakov. M: Music, 1967. With 209.

[6] Spitta Ph. Johann Sebastian Bach. Leipzig: Breitkopf und Härtel, 1880. R. 154.

[7] L. Auer. My school of violin playing. M: Music, 1975. S. 139-140.

[8] F. Dosse, Paul Ricoeur. Le sens d'une vie. P., 2001. R. 38

[9] P. Hindemith Collection of articles and research / edited and compiled by I. Prudnikova. Moscow: Soviet composer, 1979. S. 35 